\title{
Significance of Medium of Instruction and Personality in Designing Adaptive e-Learning Systems
}

\author{
Damodaran Venkatesan \\ Research Scholar \\ Anna University of Technology, Tiruchirapalli, \\ Tamil Nadu, India \\ Dr. RM. Chandrasekaran \\ Professor, Annamalai University, Chidambaram \\ Tamil Nadu, India \\ Dr. A. Velangani Joseph \\ Assistant Professor, Department of Management Studies \\ Anna University of Technology, Tiruchirapalli, \\ Tamil Nadu, India
}

\begin{abstract}
The growth of internet over the years has generated greater interest in e-Learning as a tool for bringing the training to the learner's door step. Well-designed e-Learning can offer the right mix of text, audio and video content to enhance the understanding of the learner. This paper investigates the impact of learner's primary medium of instruction (MI) at school in understanding the technical content given to them in English and proposes a design for developing an Adaptive e-Learning (AeL) system personalized to the learner. Based upon the significant gap in the performance between the regional language medium students and English medium students, the decision procedure rules for providing personalized content to the learner were developed. The AeL system personalized to the leaner was successfully implemented with the help of an extensive survey to bridge the gap in performance between the regional language medium students and English medium students. It was further investigated whether learner's personality influenced the performance when AeL offers the course contents in certain structure.
\end{abstract}

Keywords-Components: e-Learning (eL), Adaptive e-Learning (AeL), MI, Personality, Urban / Rural Capacity gap

\section{INTRODUCTION}

E-learning has a major role in making education more accessible and affordable to the learner in any part of the world. It has revolutionized and re-invented the potential of academic institutions. All the features and benefits associated with eLearning are applicable to AeL as well. On top of it one important feature that distinguishes the AeL from e-Learning is the adaptivity. Adaptive e-Learning (AeL) system creates a personalized environment for the learner. Personalization helps to display required content in understandable and desirable form and prevents unwanted contents being displayed, thus saving cost and time. The adaptivity can be with respect to the pace at which contents are offered, presentation methodology and also the sequencing of contents.

The focus of this research is primarily on countries offering school education both in English medium and in their regional languages. In countries like India, English is the MI primarily at urban places, and the regional languages are primary $\mathrm{MI}$ at rural places. Students from either of these MI in the school system due to limited choices end up joining professional degree courses in English medium. This study is also applicable to English-speaking countries with student immigrants from across the globe.

\section{Organization of the paper}

Section 2 deals with an experiment offering a Technical test in English using e-Learning to evaluate the impact of regional language to understand a technical subject. Section 3 discusses the design and implementation of an AeL system using Moodle with decision procedure rules for providing personalized content to the learner to bridge the gap in performance between the regional language (Tamil) students and English medium students.

\section{IMPACT OF MI IN UNDERSTANDING ENGLISH}

The hypothesis of this experiment is that the primary MI at school has greater impact than the urban / rural exposure to the student, while understanding the technical contents given to them in English.

\section{A. Participants}

A heterogeneous group of 442 number of undergraduate first year engineering students from two colleges, with a combination of regional language and English as their primary MI at school (281 regional language and 161 English medium students), but with similar pre-requisite subject knowledge (all of them scored entry level cut-off marks between 170 to 190 marks out of 200 marks to get admitted into the engineering degree programme). Even students, who did their schooling in regional language, had English as one of their subjects throughout their schooling.

\section{B. Evaluation Procedure}

In this experiment students were asked to take a test on 'Technical proficiency'. Uniform technical content was shown to all the participants through e-Learning platform. The 
students were given a total of 40 minutes to go through the contents and answer 10 questions based on the contents. One of the basic science subjects in the first year, Physics has been chosen. 'Physics' has been chosen for the reason that it offers more scope to experiment the 'adaptive' concept than Chemistry and Mathematics, where equations dominate the content. The findings from this experiment indicates that even in the case of technical content given in English using eLearning, the MI at school has a major role, as the English medium students performed much better compared to regional language students.

\section{Results and decisions}

TABLE 1

\begin{tabular}{|c|c|c|c|}
\hline $\begin{array}{c}\text { Medium } \\
\text { of Study }\end{array}$ & $\begin{array}{c}\text { No. of } \\
\text { Students }\end{array}$ & $\begin{array}{c}\text { Technical } \\
\text { Content Test } \\
\text { Score - Avg } \\
\%\end{array}$ & $\begin{array}{c}\text { Range } \\
\%\end{array}$ \\
\hline Regional & 281 & $42.39 \%$ & $32 \%-58 \%$ \\
\hline English & 161 & $72.92 \%$ & $55 \%-85 \%$ \\
\hline
\end{tabular}

Table 1: Technical Test Performance

Table 1 summarizes the task performance of the impact of MI in understanding English. The findings from this experiment indicates that the MI at school play a major role compared to other demographics, as the English medium students performed better compared to regional language students. Significant gap is noticed between regional language students and English medium students. The cut-off marks, economical and educational background of their families and the gender of the student have minimal impact.

\section{PROPOSED ADAPTIVE E-LEARNING MODEL}

Addressing the limitations of current e-learning platforms, we propose and design a model for adaptive e-learning. The fundamental concept of this model is that authors create a bunch of individual learning objects, which are combined to form personalized courses according to each learner's capability. According to this model, learners are characterized based on their primary MI at school and other demographics.

The proposed AeL is developed using Moodle Learning Management System. Voluntary input obtained from the learner and assessment results are used to personalize the content offered to the learner.

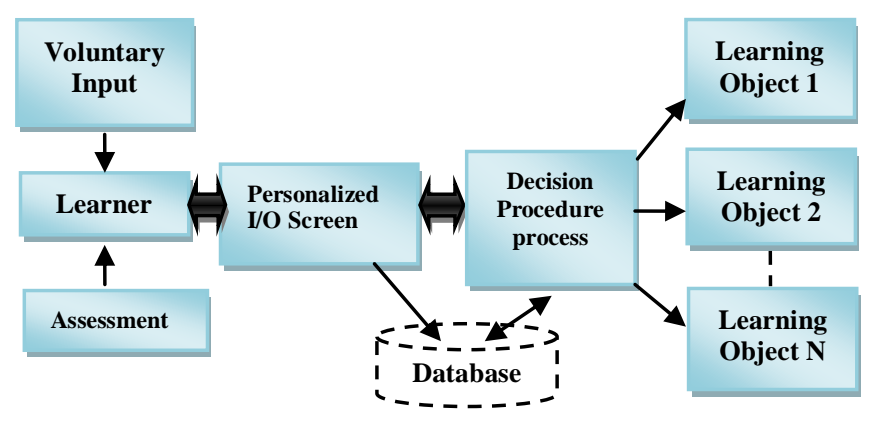

Figure 1: AeL Framework
International Journal of Computer Applications (0975 - 8887)

Volume 8-No.13, October 2010

There are various modules with different functionality in the proposed adaptive e-Learning model (Figure 1). The following information is voluntarily obtained from the learner: Age, Educational qualification, Urban / Rural, MI at School, familiarity with English language, gender, etc. Prior to start of a course the learner's proficiency in the subject is tested. On completion of the course, a post-test is given to assess the knowledge level gained.

Input is obtained for the learner through the "Personalized Input-Output Screen" and recorded in the "Database". The Database acts as the central repository on the Web for the Adaptive e-Learning. Based on the information available in the Database about the learner, the "Learning Objects" to be presented is automatically determined by the "Decision Procedure Process" and presented to the Personalized InputOutput Screen. The lessons of a course are split into various learning objects and they can be customized to the regional language students as follows:

- The learning objects will display the regional language translation of English words on mouse over to a particular word.

- Present the learning objects comprising of glossary of English words and technical terms in the regional language. As and when the regional language students don't understand a certain word, they can refer to the glossary and understand its meaning in regional language.

- $\quad$ Present additional pages of course content for better understanding.

The Learning Objects can be presented in any permutation and combination as needed. For example, a course in Computer Networks with extensive content can be created. Depending on whether the learner is an Undergraduate / Post-graduate / Research Scholar the lessons will be personalized.

\section{ADAPTIVE E-LEARNING AS A TOOL TO OVERCOME THE MI BARRIER}

The hypothesis of this experiment is that AeL can be successfully used to bridge the gap between regional language students and English medium students, while understanding the technical contents given to them in English. The same set of participants who were tested in the previous experiment participated in this experiment as well.

\section{A. Participants}

The same set of heterogeneous group of 442 number of undergraduate first year engineering students from two colleges, with a combination of regional language and English as their primary MI at school (281 regional language and 161 English medium students), but with similar pre-requisite subject knowledge.

\section{B. Evaluation Procedure}

The earlier experiment was related to e-Learning, whereas this experiment is related to testing of student's performance (i.e. ability to understand) under AeL system. The participants were divided into 2 groups. The Group- 1 comprises of 161 students from English medium, the rest of the 281 students 
from regional language medium. The Course was divided into 2 Learning Objects. The Learning Object-1 comprises of Physics subject content in English only. Learning Object-2 comprises of the same Physics subject content in English with the regional language translation of English words on mouse over to a particular word and a glossary of English words and Technical terms in the regional language.

Before taking up this test, students were asked to answer 10 questions in the subject of physics. This qualifying test helped group the respondents into 'Above Agerage' and 'Below Average', based on the median score. Similar to MI the 'Knowledge level' has also been employed to incorporate the 'Adaptiveness' concept. Based on the grouping 'Below Average' participants would receive the contents involving detailed explanation for definitions and concepts and 'Above Average' participants would continue to receive the contents without indepth details.

\section{Results and Discussion}

Table 2 summarizes the task performance of the impact of adaptive e-Learning in improving the performance. The findings from this experiment indicates that the performance gap between the English medium students and Regional language students can be narrowed down by translating the English content in Regional language as and when needed. Thus adaptive e-Learning enhances the performance of the students.

\section{TABLE 2}

\begin{tabular}{|c|c|c|c|c|}
\hline Group & Course & $\begin{array}{c}\text { Test } \\
\text { Students }\end{array}$ & $\begin{array}{c}\text { Range } \\
\text { Score }- \\
\text { Avg } \\
\%\end{array}$ & \\
\hline $\begin{array}{c}\text { Group-1 } \\
\text { (English) }\end{array}$ & $\begin{array}{c}\text { Learning Object-1 } \\
\text { (English Only) }\end{array}$ & 161 & $71.38 \%$ & $48 \%-84 \%$ \\
\hline $\begin{array}{l}\text { Group-2 } \\
\text { (Tamil) }\end{array}$ & $\begin{array}{c}\text { Learning Object-2 } \\
\text { (Help in Regional } \\
\text { Language) }\end{array}$ & 281 & $62.74 \%$ & $46 \%-75 \%$ \\
\hline
\end{tabular}

Table 2: Physics Test Performance - Adaptive e-Learning

\subsection{PERSONALITY TYPE INDICATOR SURVEY}

\section{A. Survey}

To understand the relationship between personality and the preference for course structure, the respondent's personality type has to be identified. Students were directed to fill a questionnaire related to their personality types and other relevant details. Based on the score secured, the participants are grouped either as: Extravert / Introvert, Sensing / Intuitive and Methodical / Variety seeker.

\section{B. $\quad$ Course Structure}

The Physics subject content was offered in multiple pages. The learner has to voluntarily go to the next page after reviewing the contents on each page. Before the start of the course, a summary of all the topics were given for quick review. Various theories and their meanings were presented. To maintain the learner's attention, the course content was offered in various forms such as text, text + audio, and text + animation. The
International Journal of Computer Applications (0975 - 8887)

Volume 8-No.13, October 2010

learner is not aware of the type of content to expect when he moves on to the next page.

\section{Results and Discussion}

With the given course structure, 'Extravert' learners outperform 'Introvert'; 'Variety seekers' score is significantly higher than 'Methodical'; and 'Intuitive' students have shown better performance than 'Sensing' students. Among these personality types 'Variety Seekers' (Time taken, performance score, No.of navigations and No.of revisits) are found to receive the maximum benefit through AeL.

\section{CONCLUSIONS AND FURTHER WORK}

The findings from the first experiments indicated that when content is offered in English, the MI at school is more significant compared to the region the student hailed from. The primary objective of this research is to bridge the gap between the two sets of sample so that regional language students will perform as good as English medium students. This has been achieved by developing an adaptive e-Learning model (as detailed above) to personalize the content based on the profile of the student and other relevant factors. The findings from the second experiment indicated that the performance gap between the English medium students and Regional language students narrowed down significantly by translating the English content in Regional language on mouse over to a particular word and by offering a glossary of English words and Technical terms in the regional language. The personality survey helped differentiate the preference for the course structure between various personality types.

Future research can be expanded to include for example, adaptive e-Learning content for students from non-English speaking countries to perform on par with students from English speaking countries, when the contents are offered to them in English. The course structure can be presented personalized to the learner's personality.

\section{REFERENCES}

[1] Toshie Ninomiya, Ken Nakayama, Miyuki Shimizu, Fumihiko Anma and Toshio Okamoto: The Design of eLearning Environment Oriented for Personalized Adaptability, Seventh IEEE International Conference on Advanced Learning Technologies (ICALT 2007).

[2] Feng-Hsu Wang: A Contextualization Method of Browsing Events in Web-based Learning Content Management System for Personalized Learning, Seventh IEEE International Conference on Advanced Learning Technologies (ICALT 2007)

[3] Zhou Xiang: Design and implementing An integrated Learning Content Management System, 0-7695-3090-7/08 (C) 2008 IEEE

[4] Sabine Graf: Fostering Adaptivity in e-Learning Platforms: A Meta-Model supporting Adaptive courses, Research funded by Austrian Federal Ministry for Education, Science and Culture and European Social fund (2002)

[6] Amal Al-Dujaily*, Hokyoung Ryu: A study on personality in designing adaptive e-learning systems, 978-0-7695-31670/08 @ 2008 IEEE. 
[7] Amal Al-Dujaily*, Hokyoung Ryu: A Relationship between e-Learning Performance and Personality, Proceedings of the Sixth International Conference on Advanced Learning Technologies (ICALT'06).

[8] Daniela Reddig, Joyce Karreman, Thea van der Geest: Watch Out for the Preview: The Effects of a Preview on the Usability of a Content Management System and on the Users' Confidence Level, 978-1-4244-2086-5/08 (O2008 IEEE.

[9] Jurriaan Souer, Paul Honders, Johan Versendaal, Sjaak Brinkkemper: Defining Operations and Maintenance in Web Engineering: a Framework for CMS-based Web Applications, 1-4244-1476-8/07 @2007 IEEE.
[10] Farah Habib Chanchary, Indrani Haque, Md. Saifuddin Khalid: Web-Usage Mining to Evaluate the Transfer of Learning in a Web-based Learning Environment, 0-7695-30907/08 (C) 2008 IEEE.

[11] Personality Profile: Personality100.com

[12] Tsandilas, T., \& Schraefel, m. c. (2005, April 2-7). An Empirical Assessment of Adaptation Techniques, Paper presented at the CHI, Portland, Oregon, USA. 